\title{
Fructal Turnaround Through Strategic Cognition And Congruent Changes In Distribution System
}

Melita Balas Rant, University of Ljubljana, Slovenia Pierre Casse, IEDC-Bled School of Management, Slovenia

\begin{abstract}
Toni Balažič, a young consultant who had just finished his Executive MBA study at a leading CEE Business School, was invited to serve as a CEO of Fructal, a fresh juice company, where he had been working as a cost reduction consultant. Fructal is in a serious financial crisis after having undergone a series of unsuccessful CEOs, a failing market image, rising mistrust and dissatisfaction of employees, negative sales trends, negative EBIT, rising problems and conflict within the distribution channel, and unclear strategic expectations from the mother company. Toni accepts the nomination aware of the risk for his career if he fails. Even with strong support from the president of the mother company, Toni faces a high level of mistrust among employees and old members of the management board, and an inward, product-oriented culture with a low market emphasis. After bringing new people to the management board, Toni restates the company goals: (1) streamlining operations and cost reductions; (2) open internal communication; (3) enlargement of the geographic focus; (4) innovation; and (5) development of new distribution models for each country. Though Toni successfully fulfills these goals, he fails to overcome a sense of unrest and worries about the business. The case is structured to enable students to grasp the profile of a turnaround leader, practice the analytical skills of problem identification, search for solutions, and discuss a turnaround strategy that emphasizes "distribution." The case is suitable for post-graduate students of management, short duration executive education programs, executive MBA programs, and entrepreneurship education.
\end{abstract}

Keywords: Food Processing; Crisis; Market Fragmentation; Leadership Traits; Cognition; Inertia; Change; Distribution System

\section{INTRODUCTION: LEADING IN A TOUGH TIME}

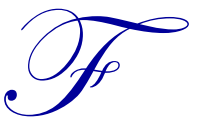

ebruary 2009. It's cold and snowy outside. Toni Balažič is struggling. Maybe he made a major mistake by accepting the position of General Manager at Fructal. Yes, there was no question that it had been a challenge. But also - in a way - a trap! The situation was so bad at the beginning of 2007. He was supposed to fail and yet surprise, surprise he had turned the entire situation around - to the astonishment of everybody but himself. He knew he could do it. He had done it. What an achievement! And yet he didn't feel so good about it. Why? Something in the deep recesses of his mind was bothering him...But what? A trap...Where?

\section{TONI BALAŽIČ: A LEADER IN ACTION}

Toni Balažič was never willing to submit to a mediocre way of thinking. Instead, he always challenged himself to think in novel ways, to explore different possibilities. He didn't allow himself to shrink from the threat, difficulty, or pain. On the contrary, he had the perseverance to finish what he had started; to stick to a desired goal and stay flexible on the way there. He liked people and enjoyed working in teams. People, who got the opportunity to communicate with him, even for just a while, were always left with a warm feeling of appreciation. He was kind, even when he was sharing problematic stuff. He was a good persuader, negotiator, and networker. 
His powerful zest for life was immediately apparent. It seemed he felt good in his skin. Physically, he had a healthy, athletic figure of medium height, short dark hair, and a gentle face with sparkling brown eyes. And indeed Toni, by the age of 35 , had already experienced unqualified success.

He started working early, at the age of 20, as a program manager and project manager at SPEM, the second largest public relations agency in Slovenia, and one of the biggest in Adriatic region. He soon excelled as a high caliber employee, to whom the most challenging communication projects were assigned. Projects like the Environmental Fund of the Republic of Slovenia, Tetra Pak, Henkel Slovenia, Petrol, The Coca Cola Company, and Mariborska livarna were his projects. He implemented all of them successfully. In 1997, he graduated from marketing at the Faculty for Economics and Business in Maribor. Afterwards, he served as a part-time teaching assistant in business communications for two years. In addition, he took over the position of a part-time director at the London School of Public Relations (LSPR), Slovenia. There he earned a PR professional certificate and also added the certificate of Accredited Business Communicator in 2000. The latter was granted to only 400 experts worldwide by the International Association of Business Communicators (IABC), the leading global association of communication professionals.

Toni effectively launched the LSPR brand in Slovenia. Based on that, he was invited to be a member of an international team responsible for launching the same brand in Croatia. During the Croatian project he was in charge of a merger between the two main Slovene PR agencies, Spem and Pristop. From 1992 to 1999 he was officially employed at SPEM. His widely diverse activities around numerous communication and business projects made his business talents apparent to many managers in Slovenia.

So, not surprisingly, in 2000 he was offered the job of marketing director at PETROL, the second biggest Slovenian company, active in energy and retail business, and one of the top 15 transnational companies in Central and Eastern Europe. It was rare that someone below the age of 30 was appointed to such an influential position with responsibilities in charge of the planning, implementing, and controlling of marketing and communications activities for all companies in the Petrol Group. The Petrol Group included B2C and B2B activities in oil and gas, electricity, convenience shops/retail, environmental projects (like cleaning facilities), paying/loyalty cards, lubricants, and tourism/restaurants across many geographic markets (Slovenia, Croatia, Bosnia and Herzegovina - BiH, Serbia, Montenegro).

Toni said yes to the Petrol opportunity. With all his willpower and ambition he tried to set up a modern marketing function with a clearly defined strategic focus. He led a team of 12 people around the activities of market research, communication strategy and brand management, advertising, and sales promotion. He pushed them all to address emerging market challenges and dilemmas upfront, to discuss them openly, and to find the best possible solutions. His team delivered many notable contributions to the competitive position of the company.

In 2005, he began his Executive MBA studies at the IEDC-Bled School of Management. At the entry interview the EMBA program director marked him as: "An analytic thinker; tries to approach problems from many sides; doesn't jump to conclusions; able to change his mind in light of evidence, and ready to give others a fair chance to express their opinion."

Toni's abilities became apparent to the people from AT Kearney, a global management consultancy and the leader in the SEE region, who were consulting on MBA projects. Therefore, the invitation to serve as AT Kearney consultant came and Toni switched jobs again. From January 2006 to January 2007, he began the position of a management consultant with an expertise in marketing and sales. He worked on three projects, one of them Fructal. Toni remembered the latter as: "Fructal's performance scissors with decreasing sales and increasing costs had been cutting company value for several consequent years. Something urgently needed to be done to preserve the company. AT Kearney was appointed to develop a short-term growth program with an outline of a long-term strategy."

At the end of 2006, on the morning of Christmas Eve, Toni was invited for coffee by Boško Šrot, president of the board of Laško Brewery, the indirect owner of Fructal. The coffee meeting was very friendly, and then the offer came, in which Mr. Laško put it very simply: "I want you on the board. You have what we need and frankly I am ready to do almost anything to get you. Pick any key position you want (but...mine) and it is yours!" 
After some consideration Toni decided to go for this challenge and transform Fructal in the role of CEO. The mission of bringing Fructal back on track seemed challenging, but not too difficult. After all, Fructal was still a brand which even the scare on excessive levels of radioactive substances in Fructal blueberry products (in the summer of 2004) couldn't endanger much. The research results on how the scare hit the perception of the Fructal Brand in Slovenia, Croatia, Serbia, and $\mathrm{BiH}$ showed that. "Fructal remains ranked as the leading juice brand in Slovenia and Bosnia-Herzegovina, third in Croatia, and fifth on the Serbian and Montenegrin market.”

\section{THE BREWERY LAŠKO GROUP}

Fructal was part of the Laško Brewery (Web profile of Laško Group, 2010), a holding-concern type of company that acquired nine companies: FIRMA DEL from Laško, Ra\&LA from Sarajevo, Jadranska pivovara from Split, Brewery Union from Ljubljana, Vital from Mestinje, Radenska from Radenci, Slovenian newspaper company DELO from Ljubljana, and SLOVITA from Moscow. Besides, Laško Brewery, Union Brewery, and Radenska jointly owned $23.3 \%$ of Mercator, a big Slovenian retail chain with businesses spread across Slovenia, Serbia, Croatia, and BiH. Union Brewery owned Fructal from Ajdovščina, which owned Fructal Zagreb, and Fruktal Mak from Skopje.

After the acquisition wave, the group's core remained the production of beer, in addition to non-alcoholic beverages (mineral, spring and natural waters, soft drinks, fruit juices, syrups), which merged with retail and wholesale activities. In the brewery segment, the Laško Group held $87 \%$ of market share in Slovenia and almost $15 \%$ in other Western Balkans countries. Both Laško and Union breweries were also producing and selling natural drinking water. Moreover, Union was also producing fruit juices and ice teas, the same as Radenska, whose core activity was the production of mineral and natural drinking water. Both Fructal and Vital were in the production of fruit juices and syrups.

Though many of the companies within the group were direct competitors with each other, struggling to gain the same customers, the main reason for putting them under one roof was the ambition of the Laško Group to become one of the key players in the beverage industry in South Eastern Europe. This goal was supposed to be achieved through the consolidation of the affiliates' brands and synergies rising from the common purchasing and distribution system.

Therefore, after the acquisition of beverage companies to Laško Brewery and the creation of the Laško Group - ended 2005 by purchasing $41.32 \%$ shares of Union from Interbrew (now Inbrew) company, who decided to step out of the battle for Union - the consolidation process started. The latter produced three major organizational changes:

- $\quad$ Centralized purchasing of all raw materials and packaging for all companies in the group

- $\quad$ Centralized after sales activities for breweries

- $\quad$ Centralized distribution in the HORECA channel

All these organizational changes were supposed to create greater revenues with lower costs for all companies in the group.

\section{TAKING OVER FRUCTAL (BEFORE 2007 AND UP TO 2008)}

Fructal (Company profile of Fructal, 2010) had been one of the most known companies across borders in times of Yugoslavia. Its main products were high quality fruit juices, syrups, baby food, fruit bars, and alcohol drinks. The main production facility was located in Ajdovščina, Slovenia with affiliates in Duplica (Slovenia) and Skopje (Macedonia). Fructal Mak produced and distributed juices and beverages in Macedonia, while representative offices in Croatia and $\mathrm{BiH}$ only handled the distribution activities in their respected countries.

When Toni officially became appointed CEO on February 1, 2007, the company was already deep into red figures. In 2006, losses increased from $0.3 \mathrm{~m}$ EUR in 2005 to $3.24 \mathrm{~m}$ EUR. All together Fructal's struggles caused a great deal of bad publicity in the business community, making the public image of Fructal less and less dazzling. 
Toni approached the Fructal business situation very pragmatically: "Negative trends in sales, market shares, and P\&L measures were the obvious problematic symptoms. Fructal was losing market share in traditional markets more than ever. To my mind, a lack of innovation was the root problem behind the losses. From my childhood, I remember many TV commercials presenting novel products by Fructal. This explorative character vanished completely. Besides, there was no real motivation on the side of distributors. Last, but not least, increasing costs were symptomatic too, caused by inefficient cost controls."

Toni was also concerned with softer issues coming from the employee side: "What struck me up front was the strange perception of me. I came from AT Kearney, which was perceived to be there to cut costs. As a result, gossip spread that I must have come there to sell off the company. This was an absolutely misleading idea that pressured me a lot at the beginning. Next, what initially alarmed me was the stiff, rigid, and closed corporate culture. The company was filled with anxiety and apathy. Employees were fed up with frequent CEO changes without progress. They were afraid for their future. A strong hierarchy and military-like atmosphere in a sense "I ordered you ... I was ordered to..." prevailed. Next, the employees' mindset was product-oriented. "High quality product" was the value, which is good, but on the other hand there were no discussions about customer needs and desires, or about market trends. Apart from all that, the management team also surprised me to some extent. The views of some executives were simply too short-term for the challenges ahead."

Toni immediately started to intervene on those burning issues. In the first year and a half, he changed five of seven key managers: two were brought in from the outside, the Chief Financial Officer and Chief Marketing Officer; two were brought in from the R\&D department, and the previous head of production returned to Fructal. Due to this restructuring of top management the average age decreased to 37 years. Toni hoped that a rejuvenation of the management team would have a positive impact on the overall organizational culture - make it more open and customer-oriented.

Toni was trying to create openness in communication with his attitude towards employee involvement in decision making: "I want to create rich discussion on the topic ahead before making a final decision. I want to engage others and make them speak up openly and think deeply about customer needs, desires, and aspirations. I want their ideas clarify. I want them to become motivated by their own ideas."

One day during his full immersion into the Fructal recovery Toni received an anxious message from his colleague: "Some people have asked me to tell you that you should be careful what you do with Fructal. If you mess the company, they might come after you...."

Though this strange encounter added steam into an already pressured situation; it also convinced Toni to turnaround the company as soon as possible. Though he was appointed to develop the company strategically, he also needed to generate good results in the short run. There was no time to waste. Toni focused even more on cost cutting to stop the leakage of company's resources: "I have focused especially on costs related to the work force, the main financial drain. I have tried to reduce the number and power of employees in a nice, gentle way. I also decided for some extensive cost cutting in purchasing."

But Toni knew that cost cutting alone was not enough to rise above the zero profit bar. He needed to improve the inflow of resources to the company as well: "We needed to redefine the geographical focus. We have decided to enlarge it from the Balkans to the triangle Milano - Constanza - Tirana. We kept the product categories the same, namely JNFD (an acronym for juices, nectars, fruit drinks). All together some physical changes in the distribution system and improved trust with employees and distributors were required."

Toni knew if he didn't manage to address the competition and develop a distribution model successfully, all other efforts would have had only a modest effect on the final performance results: "Distribution channels are of vital importance. They acquire important information, impact the sales as well as other elements of the marketing mix. Therefore, management of distribution channels is a key success factor in our industry." Though distribution was a key success factor, Toni as CEO of a medium-sized company owned by the Laško Group had only little discretion and control over it. 


\section{FACING THE COMPETITION: A DISTRIBUTION CHALLENGE}

In 2006, Fructal sustained relatively high brand awareness in the Ex-Yugoslavia markets, which was mainly a result of the past when Fructal held more than 50\% of the fruit juice market. An acquaintance with the Serbian police on one event confirmed that to Toni: "One day I was driving too fast and the police stopped me. I thought they would fine me severely, but when they realized I was the head of Fructal, they simply let me go. This was sort of confirmation that the Fructal brand is my main weapon against the competition."

After the separation of Yugoslavia, market battles became fiercer; strong geographically localized competition had already developed during war time. Many small fruit and soft drink producers successfully positioned themselves in their local regions, serving primarily their ethnically and price sensitive market segments. At the same time, well-known international brands like Rauch from Austria and Cappy from Coca-Cola penetrated those markets successfully. Therefore, Fructal's market share was shrinking continuously.

Next, after the consolidation of sales activities and especially when a new, centralized distribution for the HORECA channel was introduced into Laško Group, the company started to encounter additional difficulties. Although Toni didn't have a clear picture about the issues below the surface, he immediately sensed that expected distribution synergies from group consolidation would not be met, though some of the purchasing synergies were successfully implemented (i.e. lower purchasing prices, greater price stability, and extended payment dates).

The problems with sales and distributions were present in all ex-Yugoslavia countries, similar in Serbia, Monte Negro, Kosovo, and Bosnia and Herzegovina - and specifically in Croatia and Macedonia. In addition, these fragmented markets vary considerably in terms of import duties, evolution of distribution, and retail sectors (Figure 1). In Bosnia and Herzegovina the company was operating via Eurofruit, which was owned by Fructal. In 2006, Eurofruit didn't manage to enter major supermarket stores that were growing rapidly across the country, despite the fact that $\mathrm{BiH}$ was always the largest foreign market for Fructal products, generating more than 50\% of export revenues. Besides, Toni also saw other factors contributing to the sales problem: "Until the ending of bilateral agreements with $\mathrm{BiH}$ in 2004 with the admission of Slovenia to EU, Fructal was one of the biggest exporters to $\mathrm{BiH}$. After the accession, Fructal products were imposed the same taxation as other EU countries, which decreased the price competitiveness and revealed Fructal's inability to compete in more sophisticated manners." Consequently, in the period 2003-2005 Fructal all together lost 50\% of sales with a distribution index drop below $60 \%$. 


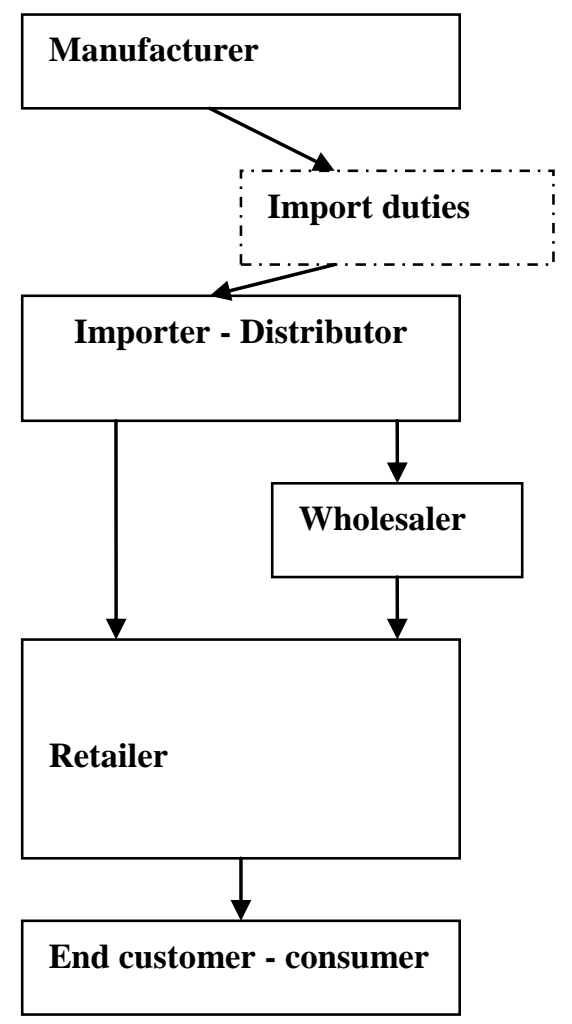

\section{Different import duties that each particular country has vary from $8 \%$ to} $\mathbf{5 0 \%}$. Furthermore, also other restrictions are posed to non-domestic manufacturers. Transport costs increase costs by another 5 to $10 \%$.

The costs of the importer (also regarded as the margin of the importer) vary between $\mathbf{1 0 - 1 2 \%}$ in countries with more importers and low purchase power. However, in countries with one importer and bigger purchase power this margin is usually between $\mathbf{1 5 - 2 0 \%}$.

Retailers usually work with margins between 15 to $30 \%$.

Finally, also VAT affects end-price and varies from 15 to $18 \%$.

Figure 1: Fructal Structure of Cost and Profit Margins Source: Fructal internal records, 2008

Similar to BiH also the Serbia, Montenegro, and Kosovo (SMNK) region shared the problem of the decreasing motivation of distributors, and hence decreasing sales and decreasing market shares. The marketing budget for these countries was used without leverage on the market: "As an end result, the low motivation of distributors, price un-competitiveness in relation to domestic industry, and significant import duties resulted in fall of the market share in Serbia below 1\% in 2006."

In Croatia, Fructal was selling its products through Fructal Zagreb. Fructal Zagreb was marked by the replacement of two directors in 2006 because they didn't manage the introduction of new packaging well, which in turn caused a 15-30\% price rise and a drop in sales by half. Boycotts of Slovenian products occurred in Konzum, the largest Croatian retailer holding above a $10-15 \%$ of market share. The concentration of retail was increasing, rapidly eating the negotiation power and market share of Fructal Zagreb. Besides, past distribution politics was "not to work with too many retailers" and Fructal Zagreb didn't own a wide portfolio of shelves.

As a consequence, more and more 'incentives' in the form of discounts were given to retailers, which resulted in a lower sales margin. Subsequently, in order to cover all discounts given, Fructal Zagreb was forced to increase prices. This decision decreased price competitiveness of the Fructal products. Moreover, instabilities in the management structure negatively affected relationships with business partners. Decreasing trust and increasing costs of control over business partners were more and more a problem. The end result was the severe crash of distribution to retailer chains, and so HoReCa business consequently and its market share dropped to less than $3 \%$.

In Macedonia, Fruktal MAK, Fructal's manufacturing subsidiary, operated positively in 2006. Fruktal MAK was responsible for production as well as for distribution of Fructal products in the country. Fructal tried to seize the opportunity, via this subsidiary, of a preferred stance from a tax perspective in the CEFTA region, supported by the bilateral agreement between Slovenia and Macedonia. Despite a positive performance, Toni believed that the business opportunities coming from the bilateral Macedonian-Slovenian agreement were not 
captured fully. In fact, he was convinced that the distribution part of the Fruktal MAK value chain was problematic: "The company has the competence in production. This is why we have it there in the first place! It is easier to control costs of production then costs of distribution. Our accounting was not able to spot the real costs of distribution. Obviously, Fruktal MAK had no real competence for distribution - no control over index of distribution, no trustworthy business partnerships, problems with payments, and insufficient human resources. The distribution part needed to be outsourced."

\section{SALE AND DISTRIBUTION DECISIONS}

Toni first decided to dismiss the concept of one unified distribution model and adapt different models suited for each country's peculiarities. According to him, "A complexity of cultural, political, economic, and business environments in Southeast Europe made the use of one distribution model for all those countries a useless strategy."

Second, Toni decided that all of the country-specific distribution models should be based on long-term cooperation with local business partners. Toni rested his decision on the following argumentation: "A countryspecific distribution approach presents the best solution in terms of distribution costs on the one hand, and geographical coverage on the other. Next, cooperation carries a lower risk of payment. Our company has no specific costs, as well as problems with physical distribution. If the country faces stern political instabilities, it is even riskier and more inefficient for the company to cover the distribution by itself. Besides, in the Balkans personal relationships and mutual trust are in many cases more important than financial incentives alone. If one can manage to build strong personal bonds with the business partners who are economically and politically strong and well organized, you are on the way to success." The overall distribution goals were: (1) to achieve an index of distribution of at least $64 \%$, which means $80 \%$ of the portfolio in $80 \%$ of the stores; and (2) to achieve at least a $10 \%$ market share in each country.

In order to fulfill these two strategic objectives as soon as possible, Toni implemented a set of distribution changes in the distribution systems in Croatia, Bosnia and Herzegovina, Serbia, Montenegro, Kosovo, and Macedonia.

In Croatia, Toni made the decision to close the subsidiary and start distributing through the distributor Orbico. This company had more than 20 years' experience in distribution in Croatia. It had a wide portfolio of multinational brands like P\&G, Milka, and Jacobs among others. In 2007, the turnover of Orbico was $175 \mathrm{~m}$ EUR. Toni saw many advantages in Orbico: "A long-term presence in the market and a diverse brand portfolio of respected multinational brands gives Orbico strong negotiation power, and allows it to work with lower margins. Next, it has good experience in distribution with a high number of people working in the area of distribution. Orbico has access to almost all retailers in the country, also to retailers that were closed to us."

For the ethnically and historically complex environment of BiH Toni decided for cooperation with many business partners of different ethnic backgrounds: "I decided to approach eight of the main importers who had good distribution experience in their region and admittance to the important points of sales. I knew if I managed to persuade them for more active sales, revenues would improve considerably. I have promised them intensive back-up in terms of promotion, personal contacts, and help in opening new doors."

That decision resulted in the organization of Fructal distribution in BiH becoming very complex. In the region of Serbian population (Republika Srbska), the biggest distributor with the largest portfolio of products was chosen. In the region of the Bosnian - Muslim population (Federation BiH) five distributors covering smaller local regions (among them Omega, Eurobest, Bingo) with access to specific points of sales in retail and HoReCa were selected. In the region of the Croatian population (Hercegovina) two distributors were chosen by the same criteria as in the case of the Federation.

In Serbia, Montenegro, and Kosovo, Toni undertook a similar approach to $\mathrm{BiH}$. In order to regain distributors' motivation for sales of Fructal products, he tried to persuade them for a more active sales approach by offering them extensive support from the Fructal side. He decided to have two major distributors in Serbia, one 
strong in the south and one in the northern part. In Kosovo and Montenegro, an exclusive partnership was established with two family-owned distributors. Both were economically sound, with good political connections and access to main distribution channels in their respective countries.

In Macedonia, Toni went for distribution via the Croatian distributor Orbico, because: "For an effective distribution system in Macedonia we needed a partner with good knowledge in distribution. Since there wasn't any, we decided for Orbico, with whom we already cooperated successfully in Croatia, and the Orbico group has its own strong subsidiary in Macedonia."

\section{8: SUCCESS BUT...!}

The performance implication of Toni's sales and distribution decision were good. Improved distribution resulted in the rejuvenated perception of Fructal among consumers and an increased market share (despite the huge competition of private labels). In 2008, Fructal market shares increased in all countries of the Milano - Constanza Tirana triangle. Fructal experienced the greatest increase of market share in Slovenia, which amounted to around 5\% points. Distribution of market shares among "juice and nectar" producers in Slovenia are shown in Tables 1 and 2.

Table 1: Distribution of Markets Shares in the "Fruit and Juice" Segment in Slovenia, 2008, in \% (Calculated from Quantities Sold)

\begin{tabular}{lccccc}
\hline & Fructal & Rauch & Radenska & Union Pivovarna & All Other Competitors \\
\hline January-March 2008 & 38.3 & 6.0 & 3.0 & 4.3 & 48.4 \\
April-June 2008 & 42.3 & 4.3 & 4.0 & 4.1 & 45.3 \\
July-September 2008 & 42.7 & 4.6 & 3.2 & 4.1 & 45.4 \\
October-December 2008 & 41.5 & 5.3 & 3.2 & 4.6 & 45.4 \\
January-March 2009 & 46.2 & 5.0 & 2.5 & 4.1 & 42.2 \\
\hline
\end{tabular}

Source: Fructal internal records, 2008

Table 2: Distribution of Markets Shares in the "Fruit and Juice" Segment in Slovenia, 2008, in \% (Calculated from EUR Sold)

\begin{tabular}{lccccc}
\hline & Fructal & Rauch & Radenska & Union Pivovarna & All Other Competitors \\
\hline January-March 2008 & 46.6 & 8.1 & 4.6 & 3.9 & 3.9 \\
April-June 2008 & 48.7 & 6.6 & 3.8 & 4.1 & 37.0 \\
July-September 2008 & 48.4 & 6.7 & 4.4 & 4.3 & 36.4 \\
October-December 2008 & 47.9 & 7.6 & 3.9 & 3.7 & 36.3 \\
January-March 2009 & 51.1 & 7.1 & 3.5 & 34.6 & \\
\hline
\end{tabular}

Source: Fructal internal records, 2008

Sales in Croatia changed from decreasing to increasing figures in money terms, as well as in physical units; market share increased from below $3 \%$ to $3.5 \%$; and the index of distribution increased from $40 \%$ to $60 \%$.

In $\mathrm{BiH}$ the results of this decision were even better than expected. A high number of distributors with different competitive brands went for increased price competition. Distributors tried to increase the sales volume of Fructal by lowering their own profit margins, leaving the Fructal margin untouched. This worked well for Fructal. In 2006-2008, Fructal increased sales by $3 \%$ and the distribution index by 20 percentage points (from $60 \%$ to $80 \%$ ).

In Serbia the distribution index improved from $15 \%$ to $30 \%$, in Montenegro from $50 \%$ to $70 \%$, and in Kosovo from $15 \%$ to $50 \%$ (for the HORECA segment even better, from 50\% to $70 \%$ ). A growing distribution index for Serbia was partly the result of centralization of retail, and intensified and focused marketing on retail. The firm growth pattern was also established in Kosovo (+ 45\% in 2008/2006), in Serbia (+ 78\% in 2008/2006), and in Macedonia (+ 24\% in 2008/2006). Still, Toni was not yet calm regarding the Serbian market: "The index of distribution around 30\% should be corrected by payment indiscipline or and significant currency risk. Our market share is still below $2 \%$, which does not carry much negotiation power. We have uncompetitive prices in relation to domestic industry, in that the premium image of Fructal brand cannot successfully beat them. Besides, we are still exposed to some trade barriers and the centralization of retail is underway." 
Because the decision for employing Orbico as exclusive distributor for Macedonia was made recently, financial implications of that decision were not yet clear. But, Toni has expected favorable outcomes: "By outsourcing the distribution we have already managed to improve the profitability of Fruktal MAK. Next, I expect payment discipline to improve. Instead of having problems with 1,000 buyers with extremely low payment discipline, we are now dealing with just one, reliable customer. It takes a bit longer to see the effect on the index of distribution and market share. I think the index of distribution should rise from the current $40 \%$ to more than $60 \%$ in 2 years' time."

Alongside with distribution streamlining, Toni focused on innovation as the key to growth and value added. His goal was to develop and launch a line of new trendy products (i.e. smoothies, nectars without sugar, and juices with only healthy additives) for different customer segments. The first success came in 2008 with the launch of the Fructal Smoothie brand. Six months after launching, the average consumption of Fructal Smoothie in Slovenia reached the average consumption of smoothies per capita in Western Europe. In the same year the Fructal Smoothie brand was rewarded with an Effie award. Soon after its smoothie success, brand Fructal Benefit, and many new juice flavors followed. All together in 2007 and 2008, Fructal has launched 86 new SKUs (whereby SKU is abbreviation for stock keeping units). At the same time - decreased product complexity from approx. 540 SKUs to 370 SKUs. In addition to the Effie award, the company started receiving many other superbrand awards in Slovenia, Croatia, and Bosnia and Herzegovina, and climbed up the annual reputation rankings considerably. The most prestigious rewards were given to vegetable-fruit juice, beet root vegetable juice, grapefruit juice, strawberry juice, blackcurrant with iron added, and many other new juices coming from Fructal innovation activity.

Toni was still working intensively on internal communications, trying to make them more open. He also introduced annual performance interviews. Slowly, but firmly he was transforming the corporate culture towards customers' needs and aspirations. In 2008, all these actions caused EBITDA to double in respect to 2006. Improved company performance, successful initiation of the new product brand Smoothie, and other quality awards improved Fructal's reputation. As well, Toni's reputation as Fructal's business leader was firmly acknowledged, lending Fructal as the $11^{\text {th }}$ most reputable company in Slovenia.

\section{CONCLUSION: TIME FOR SATISFACTION! INSTEAD...}

Growing sales, growing market share, growing index of distribution, motivated distributors, costs under control, successful innovation activity, desired transformation of organizational culture, exceeded performance goals in terms of EBITDA and EBIT (Table 3). Toni managed to succeed and fulfill the goals. The Fructal was in the right tract heading to the right direction. Instead, Toni didn't feel fulfilled at all.

Table 3: Financial Performance of Fructal, 2006-2008

\begin{tabular}{|c|c|c|c|c|c|c|}
\hline \multirow[b]{2}{*}{$(1,000$ EUR $)$} & \multicolumn{2}{|c|}{2006} & \multicolumn{2}{|c|}{2007} & \multicolumn{2}{|c|}{2008} \\
\hline & Fructal & $\begin{array}{c}\text { Fructal } \\
\text { Consolidated }\end{array}$ & Fructal & $\begin{array}{c}\text { Fructal } \\
\text { Consolidated }\end{array}$ & Fructal & $\begin{array}{c}\text { Fructal } \\
\text { Consolidated }\end{array}$ \\
\hline Total revenues & 60,372 & 70,642 & 64,211 & 74,999 & 60,545 & 68,807 \\
\hline Sales revenues & 56,824 & 66,685 & 58,471 & 68,734 & 58,836 & 66,849 \\
\hline EBITDA & 3,897 & 3,824 & 5,615 & 6,019 & 5,561 & 5,199 \\
\hline EBIT & $-2,933$ & $-1,646$ & 906 & 819 & 982 & 780 \\
\hline Net earnings & $-3,245$ & $-1,926$ & 4,497 & 4,519 & 1,220 & 890 \\
\hline
\end{tabular}

Source: Fructal Financial Reports, 2006-2009

Taking stock of the past was helpful, but Toni knew perfectly well that what helped yesterday was in most cases useless to meet the new challenges of today and to ensure the success of tomorrow. Thoughts were running through his mind: "The recession. How long will it last? How will it affect the company? How will customers behave? How will competitors behave? How will distributors behave? How the sales will be affected? How will the mother company behave? How will retail and market chains develop in the Western Balkans? Who will have the power? Where is the biggest risk? How much risk can I take? What should I do? What do I dare? Where should I challenge myself . . . and more deeply maybe why am I not satisfied with my leadership success at Fructal?" 
For case discussion points the following discussion questions are suggested:

- What do you think of Toni Balažič's personality and cognition? How was he acting? How was he thinking?

- How did Toni approach the internal change process (employees, costs) at Fructal? Would you like to work for Fructal and Toni?

- Was Fructal an attractive business? If yes, why did Fructal produce losses until 2007? If not, why did Fructal produce profit after?

- Did Fructal operate in an attractive industry? If offered, would you take over the CEO position of a company in crisis in an unattractive industry? Which aspects of the industry were least attractive?

- Was Toni right to focus on the "distribution" aspect of the industry? What else could he have focused on? What do you think Toni could have done differently?

- Why is Toni unsatisfied at the end of the case?

\section{ACKNOWLEDGEMENTS}

The authors would like to thank the following people whose participation made this case-study possible: Toni Balažič CEO of Fructal in 2007-2009, for openness and data sharing, Danica Purg - Dean and President of IEDCBled School of Management for supporting and enabling this case study, and Derek Abel, president of IEDC-Bled School of Management advisory board, for his comments and suggestions.

\section{AUTHOR INFORMATION}

Melita Balas Rant is an Assistant Professor at the Faculty of Economics, University of Ljubljana and chair for open and in-company programs at the Center for Business Excellence of Faculty of Economics. She teaches courses on organizational design, organizational change, leadership, and strategy. She is the former Director of Executive MBA programs at IEDC-Bled School of Management and research coordinator at CEEMAN. Her research interests are the psychology of strategic leadership, leadership, social capital, organizational inertia, and business model design. In this area she has published several scientific and professional articles and cases. E-mail: melita.balas.rant@ef.unilj.si (corresponding author)

Pierre Casse is Leadership Chair at the IEDC-Bled School of Management and Professor at the Moscow School of Management (Skolkovo-Russia). He teaches at Steinbeis University (Germany), at the IAE of the University of Aixen-Provence, France (as well as at the Solvay Business School-Brussels), and the Kellogg School of Management (Northwestern University in Chicago-USA). He is a former Associate Fellow at Oxford and a former full-time faculty member at IMD (Lausanne-Switzerland). He held the "Suez Chair of Leadership" at the Solvay Business School (ULB-Brussels) from 2004 to 2006. His areas of expertise include Organizational Behavior, the Global Market and Cultural Differences, International Negotiations, and Strategic Leadership. E-mail: pierre.casse@gmail.com

\section{REFERENCES}

1. Company profile of Fructal (2010). Retrieved April 4, 2010 from http://www.fructal.si/

2. Fructal Financial Reports (2006-2009). Retrieved April 4, 2010 from http://www.gvin.com/

3. Web profile of the Laško Group (2010). Retrieved April 4, 2010 from http://www.pivo-lasko.si/ 